\title{
Innovative Technological Potential as the Basis of Mining Regions Sustainable Development in the Era of Knowledge
}

\author{
Oleg Kalenov ${ }^{1, *}$, Sergey Kukushkin ${ }^{2}$, and Raisa Kamanina ${ }^{3}$ \\ ${ }^{1}$ Plekhanov Russian University of Economics, Academic Department of Industrial Economics, \\ 117997, Moscow, 36 Stremyanny lane, Russia \\ ${ }^{2}$ Plekhanov Russian University of Economics, Academic Department of Organizational and \\ Managerial Innovations, 117997, Moscow, 36 Stremyanny lane, Russia \\ ${ }^{3}$ Moscow University for Industry and Finance «Synergy», Academic Department of Commerce and \\ Trade, 125190, Moscow, 80 Leningradsky Prospekt, Russia
}

\begin{abstract}
The increasing role of human capital, knowledge and high technology indicates the formation of a new stage of economic development - the knowledge economy, from which innovation becomes an integral part of business. However, in terms of innovation development, Russia lags behind the western countries several times. At the same time, the development of Russian regions is extremely uneven. First, it concerns mining regions. For analysis, a key mining cluster of Russian Federation was chosen - Kemerovo Region. The article assesses the innovative potential of the region, and identifies the most pressing problems that impede its integration into the knowledge economy. Solving existing problems should be carried out through a set of measures aimed at developing partnerships of government, mining science and mineral resources extracting business, creating conditions for attracting and retaining highly qualified specialists to the mining enterprises, creating an appropriate infrastructure, increasing the region's investment attractiveness, developing interregional and international cooperation in the field of subsoil extracting management.
\end{abstract}

\section{Introduction}

Currently, there is an active phase of the formation of a new type of society - informative one, with its inherent economy - the economy of knowledge. This stage is characterized by the fact that the basis of long-term economic growth here are mainly intense factors, provided by the active development of the most progressive achievements of science and technology. At the same time, knowledge is becoming the main factor in the growth of well-being both of the state as a whole and its individual regions. Innovation is one of the main products of this process, and innovative development is the basis for integration of mining regions into the new economy.

From the point of view of the formation of the knowledge economy, Russia is still

${ }^{*}$ Corresponding author: oekalenov@yandex.ru 
significantly behind the leading countries, but national potential is enormous, not only applied to raw materials, but also to science, education, culture. For the successful integration of Russia into the knowledge economy, it is necessary to start this process precisely from the regions as part of the country's territorial economic system. However, not all regions are characterized by the equally high level of innovation and technological development, and knowledge-intensive processes, which are the "cornerstone" of the formation of a new type of economy. The economy of mining regions is based, as a rule, on low-tech and ignorance-intensive production, mainly related to the primary sector of the economy. Therefore, for their successful integration into new economic realities, special tools and methods are needed that would take into account all the specifics of such regions.

\section{Materials and Methods}

The issues of economic development in general, and innovation development in particular, the formation and spread of innovations, are widely discussed in the works of both Russian and foreign researchers, among which there are publications by the following authors: G. Mensch [1], J. Schumpeter [2], N. Kondratiev [3], S. Glazyev [4], S. Zhironkin [5], and others. The problems of innovative and technological development of regions are examined in the works of E. Dotsenko [6], A. Kovalev [7], V. Frolova [8]. Various aspects of the formation of the knowledge economy were considered in the works of F. Makhlup [9], V. Makarov [10], and others.

The key industrial region of Russia, the Kemerovo region, was selected for the study. It accounts for over $55 \%$ of coal production in the country, a significant part of iron and steel output, as well as the production of finished rolled ferrous metals. Based on this, the problem of innovation and technological development of Kemerovo region is of special significance.

\section{Results and Discussion}

To ensure a high level of socio-economic development of the region and compliance with the world's leading mining regions, it is necessary to keep up with scientific and technological progress [11]. The creation of measures to stimulate innovation activity cannot achieve positive efficiency if the preliminary level of innovation and technological development of the region is not properly assessed. That is, it is necessary to trace how the region has developed in this area for a long time.

In the structure of the gross regional product of the Kemerovo region in 2016, the main economic activity was minerals mining - 29.7\% (in $2005-27.1 \%$, in $2010-31.4 \%$, in 2015 $-25.6 \%$ ). As can be seen from the Tab. 1, the production index in the region, as well as in Russia as a whole, varies in steps. In 2010 , it reached a peak value and amounted to $109.6 \%$, in 2011 - a sharp decline to $98.1 \%$, then fluctuations in the range of $101-107 \%$. In the Siberian Federal District (SFD), a rise is also observed in $2010-142.2 \%$. By 2015, the figure drops to $101 \%$, and then again to $106 \%$ in 2017 . At the same time, in the Kemerovo region, along with the Irkutsk, the situation is more stable than in other mining regions of Siberia. This indicates a more favorable environment for the development of the mining industry.

Table 1. Production indices by type of economic activity "mining and quarrying", in $\%$ to the previous year [12]

\begin{tabular}{|c|c|c|c|c|c|c|c|c|}
\hline Territory & $\mathbf{2 0 1 0}$ & $\mathbf{2 0 1 1}$ & $\mathbf{2 0 1 2}$ & $\mathbf{2 0 1 3}$ & $\mathbf{2 0 1 4}$ & $\mathbf{2 0 1 5}$ & $\mathbf{2 0 1 6}$ & $\mathbf{2 0 1 7}$ \\
\hline Russian Federation & 103.8 & 101.8 & 101 & 101.1 & 101.4 & 100.3 & 102.5 & 102.1 \\
\hline
\end{tabular}




\begin{tabular}{|c|c|c|c|c|c|c|c|c|}
\hline Siberian Federal District & 142.2 & 111.5 & 113.5 & 109.2 & 103.4 & 101 & 104.7 & 106 \\
\hline Krasnoyarsk County & 107,8 & 117.6 & 120.8 & 115.9 & 103 & 99.6 & 101.7 & 108.3 \\
\hline Irkutsk region & 133.6 & 152.6 & 133.2 & 109.7 & 110.9 & 113.6 & 112.1 & 104.7 \\
\hline Kemerovo region & 109.6 & 98.1 & 104.5 & 101.4 & 104.2 & 102.6 & 106.7 & 103.6 \\
\hline Novosibirsk region & 100.3 & 104.5 & 106.2 & 116.8 & 94.5 & 95.3 & 112.5 & 150.1 \\
\hline
\end{tabular}

Consider the indicator of innovative activity of organizations (Tab. 2). Unlike other regions, in Kemerovo region there is a rather low value of the indicator. In $2005-7.3 \%$ (in the Siberian Federal District - 8.1\%, in the Russian Federation - 9.9\%), in $2010-5.9 \%$ (in the Siberian Federal District $-8.2 \%$, in the Russian Federation - 9.5\%), in $2015-3.9 \%$ (in the Siberian Federal District - 8\%, in the Russian Federation - 9.3\%). The situation is worsening by negative dynamics, which lasted until 2017. However, in 2017, the value of the indicator almost doubles and is $6.2 \%$, which indicates an improvement in the situation. Comparison with world leaders in this direction is not in Kemerovo region's favor. In 2016, the value of the indicator of innovation activity of organizations was: Switzerland $-75.3 \%$, Brazil - 72.6\%, Germany - 67.0\%, Australia - 66.3\%, India - 63.7\%, China $-41.3 \%$.

Not being an innovation leader, Kemerovo region is characterized by a number of problems in creating, introducing and promoting innovations. According to some authors, the reasons for such a lag, both at the level of the Kemerovo region and in the whole country, are as follows. First, the number of personnel engaged in research and development is reduced. The low level of remuneration of scientific staff and the prestige of the profession does not provide an influx of young personnel. Secondly, the problem of intellectual and business migration, which is directly related to the outflow of specialists in the research sector. Thirdly, low financial activity, including the commercial sector in activities aimed at obtaining new knowledge and its practical application. Fourth, the lack of support from the state, not only material but also moral [13].

Table 2. Innovative activity of organizations, \% [12]

\begin{tabular}{|c|c|c|c|c|c|c|c|c|}
\hline Territory & $\mathbf{2 0 1 0}$ & $\mathbf{2 0 1 1}$ & $\mathbf{2 0 1 2}$ & $\mathbf{2 0 1 3}$ & $\mathbf{2 0 1 4}$ & $\mathbf{2 0 1 5}$ & $\mathbf{2 0 1 6}$ & $\mathbf{2 0 1 7}$ \\
\hline Russian Federation & 9.5 & 10.4 & 10.3 & 10.1 & 9.9 & 9.3 & 8.4 & 8.5 \\
\hline Siberian Federal District & 8.2 & 8.8 & 8.5 & 9.1 & 8.8 & 8 & 6.9 & 7.3 \\
\hline Krasnoyarsk County & 10 & 10.2 & 9.5 & 11.2 & 9.3 & 8.8 & 7.1 & 7.1 \\
\hline Irkutsk region & 8.7 & 6.5 & 6.9 & 8.7 & 6.4 & 7.9 & 4.8 & 5.3 \\
\hline Kemerovo region & 5.9 & 6.4 & 6.1 & 4.6 & 7 & 3.9 & 3.2 & 6.2 \\
\hline Novosibirsk region & 5.5 & 8.2 & 8.6 & 9.9 & 9.7 & 9.4 & 7.6 & 7.5 \\
\hline
\end{tabular}

All this is confirmed by the data presented in Tab. 3. As in the Russian Federation, the number of organizations performing research and development for the period 2005-2017 in Kemerovo region, it changed insignificantly: only in 2015, the figure grew by $18 \%$ (in Russia - by 16\%). In 2017, in all regions of Siberian Federal District, and in Russia as a whole, there is a slight decrease. The only exception is the Novosibirsk region. These trends can be explained by the intensification of research in response to the sanctions policy of Western states, which began in 2014.

Table 3. Organizations performing research and development [12]

\begin{tabular}{|c|l|l|l|l|l|l|l|l|}
\hline Territory & $\mathbf{2 0 1 0}$ & $\mathbf{2 0 1 1}$ & $\mathbf{2 0 1 2}$ & $\mathbf{2 0 1 3}$ & $\mathbf{2 0 1 4}$ & $\mathbf{2 0 1 5}$ & $\mathbf{2 0 1 6}$ & $\mathbf{2 0 1 7}$ \\
\hline Russian Federation & 3492 & 3682 & 3566 & 3605 & 3604 & 4175 & 4032 & 3944 \\
\hline
\end{tabular}




\begin{tabular}{|c|c|c|c|c|c|c|c|c|}
\cline { 2 - 9 } $\begin{array}{c}\text { Siberian Federal } \\
\text { District }\end{array}$ & 404 & 424 & 424 & 428 & 424 & 491 & 481 & 469 \\
\hline Krasnoyarsk County & 54 & 53 & 52 & 52 & 52 & 72 & 73 & 69 \\
\hline Irkutsk region & 44 & 46 & 49 & 51 & 45 & 52 & 51 & 46 \\
\hline Kemerovo region & 27 & 27 & 26 & 27 & 27 & 32 & 32 & 31 \\
\hline Novosibirsk region & 104 & 111 & 113 & 118 & 120 & 122 & 120 & 121 \\
\hline
\end{tabular}

The raw materials orientation of the economy of Kemerovo region has also influenced innovative developments (Tab. 4). Other mining regions significantly overtake it in this direction. In 2015, Kemerovo region presented eight innovative technologies, while the Irkutsk and Novosibirsk regions - more than twenty. By 2017, the gap is only widening.

Table 4. Developed advanced manufacturing technologies [12]

\begin{tabular}{|c|c|c|c|c|c|c|c|c|}
\hline Territory & $\mathbf{2 0 1 0}$ & $\mathbf{2 0 1 1}$ & $\mathbf{2 0 1 2}$ & $\mathbf{2 0 1 3}$ & $\mathbf{2 0 1 4}$ & $\mathbf{2 0 1 5}$ & $\mathbf{2 0 1 6}$ & $\mathbf{2 0 1 7}$ \\
\hline Russian Federation & 864 & 1138 & 1323 & 1429 & 1409 & 1398 & 1534 & 1402 \\
\hline Siberian Federal District & 64 & 126 & 151 & 123 & 116 & 92 & 107 & 124 \\
\hline Krasnoyarsk County & 6 & 33 & 38 & 24 & 26 & 19 & 35 & 31 \\
\hline Irkutsk region & 10 & 7 & 53 & 41 & 31 & 22 & 10 & 18 \\
\hline Kemerovo region & 7 & 14 & 11 & 10 & 3 & 8 & 7 & 6 \\
\hline Novosibirsk region & 23 & 53 & 31 & 26 & 30 & 23 & 30 & 33 \\
\hline
\end{tabular}

The dynamics presented in Tab. 4, caused by the spending on technological innovation. In 2005, they amounted to 1,845.1 million rubles, in 2012 - 12,978.9 million rubles, reaching their maximum. In 2013, the decline was almost 2 times - to 6662.1 million rubles, in 2014 - a decline to almost 1 million rubles, and then a sharp jump up to $3,899.6$ million rubles. In 2017, the value of the indicator decreased, but in general it remained fairly stable, and amounted to 3,314.2 million rubles. The sharp increase in the cost of technological innovation in 2012-2013. It was evidence that the economy of Kemerovo region was shaping the innovation potential for the next innovation cycle, the "surge" of activity of which manifested in the increase in the volumes of innovative goods and services. In 2014, there was a "jump" of this indicator by almost 7 times - from 3242.9 million rubles up to $21,346.2$ million rubles. In 2015, the volume of innovative products increased by another $30 \%$ and amounted to 32,435 million rubles. The period of 2016-2017 was characterized by a decline: the figure fluctuated between 25,000 and 26,000 million rubles. The tab. 5 shows the share of the cost of technological innovation and the share of innovative products and services in the gross regional product of the Kemerovo region for the period 2005-2017.

Table 5. The share of innovative products and costs of technological innovations to the GRP of the Kemerovo Region [12]

\begin{tabular}{|l|c|c|c|c|c|c|c|}
\hline \multicolumn{1}{|c|}{ Indicators } & $\mathbf{2 0 1 0}$ & $\mathbf{2 0 1 2}$ & $\mathbf{2 0 1 3}$ & $\mathbf{2 0 1 4}$ & $\mathbf{2 0 1 5}$ & $\mathbf{2 0 1 6}$ & $\mathbf{2 0 1 7}$ \\
\hline $\begin{array}{l}\text { The share of } \\
\text { technological } \\
\text { innovation spendings in } \\
\text { GDP, } \%\end{array}$ & 0.27 & 1.81 & 1.00 & 0.16 & 0.46 & 0.30 & 0.31 \\
\hline
\end{tabular}




\begin{tabular}{|l|l|l|l|l|l|l|l|}
\hline $\begin{array}{l}\text { The share of innovative } \\
\text { products and services in } \\
\text { GDP, } \%\end{array}$ & 0.62 & 0.28 & 0.49 & 2.86 & 3.85 & 2.99 & 2.38 \\
\hline
\end{tabular}

The most important factor in the efficiency of innovation-and-technological development is investment in fixed assets [14]. Moreover, in the Kemerovo region there is an problem of the depreciation of the main part of fixed assets. As can be seen from the Tab. 6, the dynamics of investment over the last decade is characterized by sharp ups and downs. So, for the period 2005-2010 investment in fixed assets almost doubled. Positive trends continued from 2013, until a sharp decline occurred: compared with 2012, investments fell by almost 20\%. The period 2015-2016 was characterized by negative dynamics, however, by 2017 the volume of investments had increased significantly.

Table 6. Investments in fixed capital [12]

\begin{tabular}{|l|c|c|c|c|c|c|}
\hline & $\mathbf{2 0 1 2}$ & $\mathbf{2 0 1 3}$ & $\mathbf{2 0 1 4}$ & $\mathbf{2 0 1 5}$ & $\mathbf{2 0 1 6}$ & $\mathbf{2 0 1 7}$ \\
\hline Kemerovo region & 267812 & 217711 & 230951 & 170470 & 165666 & 208126 \\
\hline Rate of growth, \% & 124.7 & 81.3 & 106.1 & 73.8 & 97.2 & 125.6 \\
\hline
\end{tabular}

An analysis of the sources of investment reports the following. The rate of equity and borrowed funds changes from year to year, keeping an approximate proportion of $60 \%$ to $40 \%$, respectively, plus or minus $5 \%$. Most of the funds raised are budget funds, but in 2016-2017 their share decreased. At the same time, in 2013, the budget of the Kemerovo region (5-7\%) accounted for the major share of the sources of fixed assets investments, but from 2014 to 2017 the situation is changing - the main share belongs to the federal budget.

The mono-profile nature of the economy of Kemerovo region adds difficulty in enhancing its innovation development: coal processing, which can act as an accelerator for innovation, is represented in Kuzbass by primary coal enrichment [15]. Therefore, it is quite problematic to find a place for innovations in the "production-loading-export" chain. Such industries as aircraft manufacturing and mechanical engineering, production of vehicles and equipment, communications, pharmaceuticals, etc., which are not developed in this region, are much more susceptible to innovations.

Among the problems faced by the mining region in the process of transition to a knowledge economy, we can highlight institutional one, such as deformalization of rules in the area of interaction between government and business, the significant role of administrative resource, incomplete institutional changes in the leading sectors of the Kuzbass economy and the lack of institutions for initiation of structural reforms - major venture funds and innovative banks, technic-and-innovative zones, guarantees for investments in innovation, etc. [16].

However, the central problem of innovative transformations is the lack of infrastructure, which is necessary for technological development, including the interaction between government, science and business.

The partnership of science, government and business is called the Triple Helix model. According to the concept of this model, the mandatory participation of all key partners is necessary - government, business, research and education complex, with the possibility of leadership of each of them, especially at the initial stage of the process of creating an innovative economy. The concept of the Triple Helix provides for a phased innovative development as a result of the constructive interaction of the scientific and educational complex, business and government (at the national and regional levels). Originally "Double helix" are being created - the interaction between science and business, business and 
government, etc., which then form the Triple helix. Institutions capable of performing nontraditional functions are considered as the most important source of innovation [17].

In Kuzbass, with different degrees of success, the process of forming "Double helixes" of innovative development has been launched in the following areas:

- scientific and educational complexes to business. This interaction is still underdeveloped and cannot be considered as a coordinated "spiral" of development;

- government to raw materials industry. The capacity of the raw material complex enables it to establish trusting relationships with the state "spiral" unit, which directly participates in the industry's revenues as a co-owner of large business;

- government to the rest of the business. Most of the enterprises in other industries are still in stagnation, which began at the end of the last century. Those enterprises that are able to enter the innovative market to create import-substituting products impose demand mainly on imported equipment.

One of the tools for implementing the Triple helix model should be the main element of the innovation infrastructure of the Kemerovo region - Kuzbass industrial park, located on an area of 23.3 hectares and having a floor area of 16.5 thousand $\mathrm{m}^{2}$. The infrastructure of the Technopark includes an engineering center, an industrial and laboratory building "Ecology and Nature Management", a business incubator, a co-working center, and a center for youth innovative creativity [18]. Its functions include: research of commodity and product markets, search for information about technologies; provision of infrastructure for business placement; assistance in promoting projects and technologies to target markets; assistance in reducing administrative barriers, mediation in cooperation with government and regulatory authorities; assistance in raising funds for projects at different stages of implementation; assistance in the introduction of new management technologies that increase the efficiency of project implementation.

Kuzbass Technopark contributes to the transit of enterprises of major industries to a new technological level, improving environmental management and minimizing the anthropogenic impact on the environment. For the period 2010-2017, Kuzbass Technopark supported 61 resident companies implementing innovative projects. At the same time, 22 residents were located in the industrial park. During this period, more than 360 applications for support were reviewed, 174 innovative projects passed the expert council, and 53 projects received regional tax incentives. The number of residents in 2016 was 28, including small and medium enterprises -26 . At the same time, the area occupancy is about $34 \%$.

The main measures to support residents of the Kuzbass Technopark are the reduced income tax rate $(13.5 \%)$ and the complete absence of property tax. However, not only residents are supported, but also management companies, for example, a 5\% tax rate for management organizations that use the simplified taxation system and choose incomes reduced by the amount of expenditures as the object of taxation.

According to the results of the rating conducted by the Association of Clusters and Technoparks of Russia, the efficiency of the Kuzbass Technopark in 2018 is assessed as moderately high and amounts to $98.409 \%$ of the average Russian value, which leaves quite good development prospects.

\section{Conclusion}

The priority areas for enhancing the innovation and technological development of mining regions should be:

- the development of partnerships of government, science (education) and business, aimed at solving urgent problems of the industry, including high-tech and knowledge-intensive;

- creation of conditions for attracting and retaining highly qualified specialists; 
- formation of an appropriate infrastructure, including improving the performance of existing technology parks and clusters;

- implementation of organizational and management changes, improving the efficiency and quality of management through the application of new standards and management tools, increasing the investment attractiveness of the region, improving business conditions, improving the legislative framework, as well as optimizing budget expenditures;

- development of interregional and international cooperation in the field of knowledge and innovation management.

\section{References}

1. G. Mensch, Stalemate in technology: innovations overcome the depression (Cambridge, Masachusetts, 1979).

2. J. Schumpeter, The theory of economic development (Progress, Moscow, 1982).

3. N. Kondratiev, Large cycles of conjuncture and theory of foresight (Economics, Moscow, 2002)

4. S. Glazyev, The economic theory of technical development (Science, Moscow, 1990)

5. S. Zhironkin, M. Gasanov, G. Barysheva, E. Gasanov, O. Zhironkina, G. Kayachev, E3S Web Conf., 21, 04002 (2017)

6. E. Dotsenko, E3S Web of Conf., 21,04013 (2017)

7. A. Kovalev, N. Rebrova, M. Zhidkova, E3S Web of Conf., 41, 04026 (2018)

8. V. Frolova, O. Dolina, T. Shpilkina, E3S Web Conf., 41, 04027 (2018)

9. F. Machlup, The Production and Distribution of Knowledge in the United States (Princeton University Press, Princeton, 1962).

10. V.L. Makarov Micro-economics of knowledge (MSU, Moscow, 2007)

11. S. Zhironkin, D. Khloptsov, N. Skrylnikova, I. Petinenko, O. Zhironkina, E3S Web Conf., 41, 04010 (2018)

12. Official site of the Federal State Statistics Service of the Russian Federation, URL: http://www.gks.ru/

13. O. Kalenov, E. Shavina, E3S Web of Conf., 41, 04054 (2018)

14. O. Borisova, V. Frolova, M. Livson, V. Biryukov, 41, 04028 (2018)

15. E. Dotsenko, N. Ezdina, E3S Web of Conf., 41, 04048 (2018)

16. V.V. Velikorossov, N.L. Lisenker, K.O. Anufriev, Soace paradigm of meso-level information media forming (MSU, Moscow, 2018)

17. Yu.R. Tumanyan, O.A. Ishenko-Padukova, I.V. Movchan, Terra Economicus, 16:4, 144-153 (2018)

18. Official site of the Association of clusters and technoparks, URL: http://akitrf.ru/ 